\title{
Variation in Language Use across Gender
}

\author{
Thanaa Alhabuobi \\ Department of Languages \& Translation, Taibah University, Almadinah Almunawarrah, Kingdom of Saudi Arabia
}

\begin{abstract}
This paper investigates the differences in language use across gender. This current paper accounts for this verity of use within several linguistic features. On the one hand, prestige and conformity are analyzed to determine how the two genders differ according to these two aspects. On the other hand, linguistic features: lexicon, sound production "phonology", were discussed in the light of the difference across gender. The aim was to state explanations of the existence of these differences. The outcomes of this analytical and descriptive research showed that men and women use language differently.
\end{abstract}

Index Terms-language use, gender, difference

\section{INTRODUCTION}

Many years ago, studies of language and its use began and haven't stopped since. Whether a descriptive or prescriptive approach was used for such purposes, there had always been common agreement on one side and disagreement on the other. Studies in the field of linguistics, like all fields, are always generating novel findings that explain the constant paradoxes that may appear now and then. This is the rationale for the continuous need to do more research in the field of linguistics, particularly in sociolinguistics. As a branch of linguistics, sociolinguistics had a long term of research within a wider scope since the science itself covers a lot of issues although its major subject is to study the relationship between society and language.

The scope of sociolinguistics covers the relationship between language use and gender; such an issue is still in question. Whether based on empirical, survey, or observational data, almost all research indicates that men and women use language differently. The continuum of literature contains many explanations for these differences none of which are identical. This dilemma might be attributed to the nature of the phenomenon itself in that investigating human attitudes and behaviors is fraught with obstacles like controlling the research tools, developing research methodology, developing scientific research tools, and controlling the sample within one community.

Most studies depended on either natural observations of the phenomenon, self-reporting, interviews, and speech recordings. However, even though some scientific validation is needed, no one can decline the prominence of previous studies or contemporary ones, nor can one deny differences as a sociolinguistic fact.

Holmes \& Stubbe (1997) claim that women are considered to be better listeners than men in interactional communication by using certain speech strategies. Namely, women tend to give opportunities to the addressees to participate in the speech event. Yaeger-Dror (1998) claims that boys use standard syntax less than girls do. In a review of the literature, Slobin (1996) draws attention to another aspect of language differences beyond pure linguistic attributes. He asserts that women tend to use emotional expression more than men. Slobin suggests an interesting explanation for this difference. It is attributed to the way young boys and girls are differentially treated during childhood. Girls are usually addressed by their parents with emotional, soft expressions while parents usually address boys in a more taught, orderly way. Even school teachers treat boys in a directive-based way while they use a questionbased way with girls.

Holmes (1995) suggests that women's speech is more polite than men's with a degree of reservation, and they are more conservative than men, Sadiqi (2003). Holmes claims that women's performance in language tests is better than men's in terms of "fluency, vocabulary, sentence complexity, listening comprehension, and speaking", cites in Chambers (1992). Rubin (1995) \& Corson (2001) discuss differences between men and women concerning communication type and found that women tend to use "marked" language that enables them to communicate cooperatively, men use "unmarked" language that helps them communicate competitively.

\section{RESEARCH PURPOSE}

The current research paper discusses and describes the differences between men's and women's language use. This research is descriptive and analytical; that is, in favor of its purpose. The literature indicates that studies have investigated this issue from different aspects. Among all are differences in language use in general, linguistic features, language aspects such as syntax and phonology, etc. The main purpose of the study was directed to discuss, describe, and analyze these differences.

The selected review of the literature provided rich data to discuss differences in terms of 1- dialects, prestige, and language use, 2- linguistic features, 3- conformity, 4- phonology, and 5- lexicon use. A discussion of the literature review was followed by general reflection to express the student's commentary on the body of literature. The aim was also to discuss the most important explanations of the existence of these differences. 


\section{LITERATURE REVIEW}

Linguistic differences between the "male" and "female" genders are well established, Holmes \& Stubbe (1997). Among all, the differences between men and women regarding language use had been investigated; also variation in dialects among them was an interesting field of research to many linguists. Although the amount of research on this issue is growing, no clear outcomes evidence the reasons behind these differences. In the upcoming sections, the researcher sheds light on this issue, which has been investigated by pioneers in the field of sociolinguistics from different angles.

\section{A. Across Dialects, Prestige, \& Language Use}

Yule (1996) indicates that women and men vary widely from each other in terms of language and dialects. More specifically, women tend to use a dialect that gives a sort of a high-ranking class known as "prestigious status" by strictly adhering to standard forms of the language, a claim, similarly, asserted by Eckert \& Rickford (2001). On the other hand, men are not particularly interested in showing prestige among peers in particular and within their society in general, and, therefore, we tend to find very ordinary "informal" expressions in men's speech. The author gives a very interesting instance for such expression used by men: "I done it"; however, Yule (1996) does not emphasize the ungrammaticality of such expression. More importantly, variance occurs in conversation; women are more expressive of their feelings and attitudes when they talk to each other, whereas men often dislike talking about their own experiences, rather they prefer to discuss general issues.

From a very different perspective, Romaine (1999) claims that, although most research in sociolinguistics found women's language to be "closer to the standard in Western urban societies" (p.11), research from Peru revealed a completely different result. Peru's community is typically diglossic and men are bilingual more than women. Interestingly, findings indicate that men use the prestigious $\mathrm{H}$ variety more than women.

Not surprisingly, women were found to use a dialect that differs from the one used by men. In Australia where there are various dialects, men use a distinctive dialect with each other and with women also. On the other hand, women use a different dialect within their gender and with men as well Wardhaugh (2010). Interestingly, it is assumed that children usually utilize their mothers' dialect; however, when boys get older, they switch to the dialect used by men.

Sociolinguistics research considers gender to be a factor affecting language use. In other words, gender is one variable used to understand certain linguistic phenomena socially; among all, the phenomena of linguistic differences between women and men. According to Fasold (1997), differences are natural phenomena as far as sociolinguistics is concerned. Fasold claims that typology, as a principle, "metaphorically" divides language into two types: the language of women and that of men. One the one hand, there is an influence of gender on language use. In other words, each group formulates a system that determines its identity; for example, women's speech is more formal and polite than men's, a claim also posited by Slobin, et al. (1996). On the other hand, the language construction 'linguistic properties of some languages" itself forces one gender to use particular expressions that are suitable only for its identity like "master" for men and "mistress" for women.

\section{B. Linguistic Features}

Similarly, Holmes (2008) contributes to the issue by stating that women are usually anxious about their prestige among people, therefore, they usually use a type of "linguistic features" that can preserve their status. The differences according to Holmes exist in the use of lexemes, tenses, and pronunciation. It is imperative to note that Holmes mentions research conducted by Lakoff (1975); the results showed that women of low status in America use a certain group of expressions, which were more common among women than men. The study extracted that the linguistic features of the language women use display a type of low self-esteem. This result is very interesting since it directly contrasts claims by Yule (1996).

Holmes proceeds with her claim based on Lakoff's findings that women tend to use specific types of linguistic expressions. Seemingly, they are prone to hints; for example, women avoid expressing requests indirectly. Moreover, they tend to give their speech the color of brightness using a certain level of tones and or words that are highly polite. However, the consequences were criticized by the researcher herself since they depended on observations and laboratory procedures. Also, the samples were not representative since they were restricted to university students only, so the findings lacked generalizability.

There is additional research conducted on the differences between male and female students through formal speeches. The findings revealed that women use prepositional phrases more than men, and men use progressive forms more than women (Holmes, 2008). In this regard, Trudgill (1977) also claims that in populations whose language is English, women tend to use correct forms more than men do. Although this claim was not supported by evidence but, rather, by guessing, women do so likely to preserve their class status.

In the same respect, uncertainty and politeness are discussed under the umbrella of "linguistic features". In this regard, the writer discusses the use of tag questions as a double-sided device used either to show uncertainty or a degree of politeness. Given the findings indicated, women usually show uncertainty in their speech more than men by using tag questions. However, other examples show that women intend to show politeness in their speech more than men using tag questions. 
Interaction is discussed by Holmes (2008) in terms of two issues; interruption and feedback. Interestingly, although it is confirmed by formal research, women are considered more talkative than men. However, according to TV programs such as interviews, conferences, and discussions, men seem to have the central speech act. Importantly, the author refers to a research paper describing students who met at different places (e.g., cafes, restaurants). The outcomes recorded interesting evidence. Within the same gender, interruption and interaction are equal among speakers. However, interaction and interruption are often recorded by males.

\section{Conformity}

From a different angle, perhaps, Wardhaugh (2010), citing Labvo (2001), mentions that while studies in how the two genders use language in different societal contexts -traced back to the end of the last century - proved differences, the reasons underlying these distinctions are still open to debate. It is assumed that men use different structures and vocabularies of a particular language making them distinctive in the way they use language to fulfill different roles and, of course, the same applies to women. His claim is supported by genetic, physical, and social "job, role, function" differences. Among the differences between the two genders concerning conformity to sociolinguistic values, "adherence to linguistic forms used and accepted by the society", it is assumed that women have more conformity than men, provided that they are stable and prescribed. On the other hand, men were found to have a high degree of adaptation to linguistic change; in other words, in this case, men are closer to conformity than women.

In the same vein, it is assumed by Coats (1993) that there is an opposite status between men and women in terms of their perspectives on the language derived from their commitment to social status and gender solidarity. Women usually adhere to standard values while men follow vernacular values. The two distinct attitudes toward social norms make women tend to use language that achieves some social privileges. For example, women are found to stick to RP in Britain more than men do because using this type of pronunciation confers a higher status than the vernacular accent. Investigating attitudes toward different social norms falls under the prevue of sociology and psychology. Speakers who use a high standard accent, close to RP criteria, are rated as more intelligent, attractive, competent, and more fluent, which is potentially why women tend to use a higher type of speech, that is, to gain higher status. Also, it is assumed that women usually like to preserve self-confidence, independence, and ambition.

There is another explanation for why men contrast women in this regard; that is, the strong desire to keep identity and solidarity. Both women and men are influenced by cultural factors that force each group to distinguish themselves from the other group. Therefore, the distance that women or men draw gives unity to each group. In summary, men and women like to maintain membership to their gender to assure identity; to achieve such a goal, each group insists on marking distinctiveness of speech to show solidarity to each other.

\section{Phonology}

Significant here is that the findings revealed by Wardhaugh, (2010) and Yule (1997) refer to an obvious distinction between women and men in the way they use the language to deal with the sound system. For example, in the northeast of the United States where the Amerindian language is used, women usually palatalize velar stops while men palatalize dental stops. Chukchi men, who live in Siberia to the north of Russia, speak differently than the women. The men usually don't pronounce $/ \mathrm{t} /$ and $/ \mathrm{n} /$ when found in the medial position between two vowels; women do not do so. Young Scottish girls are inclined to pronounce /t/ in words like "water" and "got", yet seemingly Scottish boys are prone to alternate the sound with a glottal stop.

However, the difference between the two genders' speech may be attributable to many factors that affect the attitude of one whose position is substantial with regard to politics, business concerns, and/or religion. Interestingly, the author indicates an example of such an issue. Margaret Thatcher, once prime minister of Britain, was advised to change her voice pitch to represent her position and to talk more slowly as well. This indicates that, sometimes, differences occur intentionally to fulfill a certain purpose; thus sociolinguistic studies are very fruitful to explore the existence and persistence of certain linguistic phenomena.

In the same vein, Trudgill (1977) posits that the American accent is used differently by women and men. It is assumed that women emphasize the manner of articulation when uttering vowels. They usually make the vowel more back, front, and higher than men. The author adds that it is difficult to pass validated judgment on the reasons behind such differences. He attributes the obstacles to the unlimited scope in which the two genders usually interact with each other thorough conversations. On the other hand, it is easier to measure differences and reasons across ethnic groups, for example.

\section{E. Lexicon Use}

Wardhaugh (2010:337) cites Lakoff (1973) saying that women are distinct in their use of vocabulary. Crucial here is that the investigation was "intuitive" as Wardhaugh himself admits, yet the results are still interesting. Women tend to use words that refer to colors in their speech more than men do. Also, women use certain adjectives like "adorable, nice, lovely, and charming" more than men. In terms of lexical emphasis, women are determined to use certain words to focus on themselves, such as "darling, fantastic, so good, such fun". The claim is that women are better known for such linguistic behavior than men. 
Not surprisingly, the linguistic features of the English language distinguish between the two genders in the use of some expressions. For example, a woman is referred to as "mistress", whereas a man is called "master". It is said, for example, "John's mistress" but not "Mary's master". The English language makes clear distinctions between the use of some words to differentiate genders. Other interesting examples are "boy \& girl", "widower \& widow". In the same vein, "John's widow" is a natural utterance but not "Mary's widower".

Similarly, Yule (1996) assures that difference in vocabulary use is a subject that appears between the two genders. Trudgill (1977), in his literature review, mentions an underlying finding from the Carib Indians. When women and men speak the same language yet different varieties, differences are found merely in the use of vocabulary. However, the author himself indicates that this variance is not explained by nor attributed to particular causes.

\section{RESEARCHER'S COMMENTARY \& POSSIBLE EXPLANATIONS}

\section{A. Across Dialects, Prestige, \& Language Use}

Undoubtedly, Yule (1996) presents rich lines of thoughts concerning differences between men and women in their respect to their language use. However, his claims are not supported by evidence, even from the simplest observational approach. Although his results are largely similar to other studies on this issue, the descriptive approach always requires both quantitative and qualitative analysis. Because Yule did not employ a qualitative approach, we can't determine, for example, why women tend to use a prestigious dialect while men tend to use a dialect that reflects normal expression rather than that of a non-prestigious position.

According to Holmes (2008), I do agree upon differences between men and women regarding language use. Whether or not females tend to preserve their social status through language, I have no problem saying that generally, women do care about their status and hence may use language as a means to fulfill their attitude. My claim depends not on experimental research but observations. The contrast between Yule (1996) and Holmes (2008) can be attributed to normal contradictions that usually appear in the humanities. However, concerning Lakoff's research, I agree with Holmes that more research is needed to explore why such differences exist between men and women. Moreover, more research is needed to generalize findings, although generalization is often hard to achieve as far as social studies are concerned.

Fasold (1997) assumes that gender is a variable in language use; this possibly indicates that there is a salient perspective in sociolinguistic research. Research is usually directed to seeking differences between the two genders in language use and correspondingly tries to find the rationale behind these differences, potentially linguistic, social, psychological, and/or psycholinguistic. Seemingly, these are factors for scientists to study the effects on the existence of such differences. The new perspective is that gender is a factor that affects language construction and language status. If the claim posited by Fasold (1997) is valid, then gender should be handled from a completely different perspective. This claim asserts that gender can affect language disciplines "syntax, morphology, phonology, etc." and language function. This leads to another issue: as there are different vernaculars within one language, is it possible to find a women's vernacular and men's vernacular? Of course, nowadays, women have registers and men have registers that distinguish each one from the other; that is why the claim of differences was discussed years ago. The new perspective reflects the effect of gender in building two new and independent systems mutually understood but each one is in contrast with the other from different aspects.

The variance found between men and women in terms of speech, in my opinion, is obvious. The two genders deal with sound production in a way that distinguishes them. However, this variance is not restricted to adults only; as indicated by Wardhaugh (2010), young children also display such differences. Over the generations, the use of a sound system varies from one generation to another. For example, our grandmothers were accustomed to a certain type of sound production that differs from our mothers and subsequently differs from ours. So, some variance also occurs within the same gender. Consequently, can we suppose that an old man speaks the same way that a young girl does? This claim is almost impossible to prove, yet there is a difference between them while approaching sound production. The attributes that distinguish men's speech from women's may be traced to many factors such as social position, job characteristics, situational purposes, and function, attitudes, and prestige.

According to research from Australia, indicated by Wardhaugh (2010), men are more inclined to a dialect that is different from women's dialect. These outcomes don't seem outlandish since the existence of gender differences in terms of language use is obvious, also Yaeger-Dror (1998); Trudgill (1977) supports that claim.

In the same vein and commenting on Wardhaugh (2010) who indicates that children show interest in using the mother's dialect, not the father's, which is a natural result for they usually have more contact with their mothers throughout their entire childhood. Significant here is that code-switching. Boys switch to men dialect after using their mothers' dialect is an underlying field; worth to be investigated and justified. However, code-switching represents more evidence of gender differences in terms of language use.

\section{B. Linguistic Features}

Concerning the other research mentioned by Holmes (2008) which found differences between male students and female students in linguistic features, namely "the use of the prepositional phrase and progressive forms". I can't say whether or not the sample is representative since the methodology was not detailed. On the other hand, no qualitative 
analysis was conducted to explain the existence of this variance between the two genders. According to my observation, I agree that expressing uncertainty and politeness is more common among women; yet, I do not know using tag questions only or other syntactic devices. However, women use other means to show politeness such as lexemic "vocabulary selection" and phonological "intonation".

Concerning interruption and interaction, I found it widely prominent to comment on the research indicated by Holmes (2008). I agree that women are talkative and like gossiping more than men, a claim that is also supported by Weatherall (2002). Yet research findings show the opposite. The question is how to treat this problem? If women like talking, then why do they have a minor role in general talks like conferences and interviews? Is sexist ideology at play? Do the society's traditions impose this type of concept so that it is reflected in social activities? I want to say that participant roles in discussions and, perhaps, in formal meetings and conferences are given to men more likely than women. There may be another reason behind this result; can we say that women avoid participating in meetings and interviews because of shyness? I can also justify this lack of interaction according to my own opinion. Women may have less knowledge and intellectual traits than men. All of my illustrations depend on observations or personal thoughts, yet research is needed to validate them.

I also want to discuss the findings indicating that males are highly recorded in talk interruption and interaction more than females. This may refer to the same contradiction I just mentioned. While women are considered more talkative than men, research indicates the opposite when women are involved in mixed-gender speech. I found no answer as to why or rationale behind it.

\section{Conformity}

A very open question rises in case of conformity. Wardhaugh (2010) posited that women conform to sociolinguistic values more than men under two conditions: stability and prescription to such values. I agree with this although no generalization can be submitted, for the study was conducted in Philadelphia. In general, women have "roughly" a sort of fear toward changes especially when it is related to their social status. So, when the situation requires a change in linguistic attitude that is not determined for them, women tend to avoid it and when there is further progress in language that necessitates change. This may be attributed to women's nature in their tendency to stability rather than change, or their high rate of anxiety labeling their psychological construction. Does this mean that women are more inclined to traditional attitudes in general? Or they just have a high degree of commitment "solidarity" to the social values that make them adhere to its linguistic norms. More research is needed in this regard.

Positing differences in speech between men and women to preserve identity and solidarity is reasonably evidenced by Coats (1993). Stating differences between men and women is based on sociolinguistic research included in his book along with statistics displayed in tables and diagrams. The inclusion of such data, whether surveys or experimental, proved satisfactory to the reader to consider the outcomes. Accounting for the reasons behind the distinction between men and women in terms of language use, and the explanations that follow are the keys to more investigations in this field.

\section{Lexicon Use}

The distinction between men and women in terms of the use of lexicon recorded valuable indications. First, the linguistic system of, for example, the English language devotes a different lexicon to describe the two genders, as indicated by Wardhaugh (2010). Perhaps, then each gender unconsciously undertakes a determinate linguistic system. Of course, this case might be restricted to some linguistic situations, as mentioned in the literature review; "John's mistress" is naturally spoken. The attitude of each gender toward the use of lexicon would deliberately be distinctive. On the other hand, we are not told why women are prone to the use of certain adjectives like adorable, fantastic, and darling; and inclined to another attitude like stressing a notion by saying "so nice". This may be attributed to the notion of impressiveness. However, the selection of the adjectives refers to some kind of stressing a certain concept, namely beauty; nevertheless, with a small degree of exaggeration, the use of adorable \& fantastic instead of, for example, beautiful.

Along a different line of thought, the differences between the two genders seem to be a fact rather than a specific linguistic phenomenon. That men and women are different from each other as the same as other attributes; physical, psychological, biological, is logical, and, therefore, close to fact. Consequently, it is important to differentiate between differences as a linguistic phenomenon and differences as a sort of fact. If differences are a specific phenomenon, then it is either permanent or temporary; in both cases, it is in flux. In this case, research to explore the underlying causes is warranted. However, if differences are a sort of fact, then investigating reasons "in my opinion" is less important than investigating the effect of these differences on gender itself, language, and social values.

\section{SUMMARY}

Not surprisingly, the outcomes did not contradict previous work on this issue. Unequivocally, men and women use language differently. The discussion of this paper shows that women tend to use a language of prestige more than men to achieve certain social status; therefore, women tend to use a more formal language. Contrary to that, men tend to use an informal language, which explains the different perspectives held by each group toward social values. In the same 
vein, toward the tenancy of preserving social class, women are highly rated to use a specific discipline of lexemes and pronunciation for such purpose. Men are less rated in this sense, they are found more informal, have no high attention to prestigious status.

Women's speech is more emotional than men; this claim is attributed to the method each gender is usually exposed to during childhood. Women are found to use tag questions more than men, in this respect, tag question use is an indication of the uncertainty and politeness women usually like to adhere to.

Form another perspective, although women are described as more talkative than men, interviews, conferences, and meeting, specifically the formal, indicates that men are initiatives while women tend to play the role of listeners. However, an interactional environment reflects another idea; women and men are roughly equal in exchanging speech in communicative conversations across the same gender. Nevertheless, men are rated higher in terms of interaction and interruption.

Each gender records a high degree of conformity and solidarity to its identity by using specific language; it seems that each group tends to distance itself from the other by devolving particular language sub-systems. It is unequivocal that men use a different phonological system; for instance, women are prone to use RP more than men in England to show cleverness, prestige, and ambition. Differences between the two genders are also at a high rate concerning the use of lexicon. Women tend to use words that imply specific senses like beauty, admiration, and emotions; men, on the other hand, are known to use a low rate of such expressions.

\section{REFERENCES}

[1] Chambers J. C. (1992). Linguistic correlates of gender and sex. English World-Wide 13. 4, 173-218.

[2] Coats, J. (1993). Women, Men, and Language. UK: Longman Group.

[3] Corson, D. (2001). Language Diversity and Education. Mahwah, NJ.: Lawrence Erlbaum Associates.

[4] Eckert, P. \& Rickford, J. (2001). Style and Sociolinguistic Variation. England: Cambridge University Press.

[5] Fasold, R. (1997). The Sociolinguistics of Language. UK: Blackwell Publisher Ltd.

[6] Holmes, J. (1995). Women, Men, and Politeness. London: Longman.

[7] Holmes, J. \& Stubbe, M. (1997). Good Listeners: Gender Differences in New Zealand Conversation. Women and Language 20. 2, 7-14.

[8] Holmes, J. (2008). An Introduction to Sociolinguistics. UK: Pearson Education Limited.

[9] Labvo, W. (2001). Principles of Linguistics Change, II: Social Factors. Oxford: Blackwell.

[10] Lakoff, R. (1973). Language and Women's Place. Language in Society 2, 45-80.

[11] Lakoff, R. (1975). Language and Women's Place. New York: Haper Colophon.

[12] Romaine, S. (1999). Communicating Gender. Mahwah, NJ.: Lawrence Erlbaum Associates.

[13] Rubin, D. (1995). Composing Social Identity in Written Language. Hillsdale, NJ: Lawrence Erlbaum Associates.

[14] Sadiqi, F. (2003). Women, Gender, and Language in Morocco. Boston: Brill.

[15] Slobin, et al. (1996). Social Interaction, Social Context, and Language. Mahwah, NJ.: Lawrence Erlbaum Associates.

[16] Trudgill, P. (1977). Sociolinguistics: An introduction. England: Peter Trudgill.

[17] Wardhaugh, R. (2010). An Introduction to Sociolinguistics. UK: Willey- Blackwell.

[18] Weatherall, A. (2002). Gender, Language and Discourse. London: Routledge.

[19] Yaeger-Dror, M. (1998). Factors Influencing the Contrast between Men's and Women's Speech. Women and Language 21.1, 40- 46.

[20] Yule, G. (1996). The Study of Language. Britain: Cambridge University Press.

Thanaa Abdulrazzaq Alhabuobi is Saudi and living in Saudi Arabia; Almadunah Almunawarrah. The researcher is 56 years old and working as a staff member at Languages and Translation Department / Faculty of Arts and Humanities / Taibah University. The researcher's current title is assistant professor. The email address is thamar_5@hotmail.com 